\title{
Comparison between the 4K ultra-high definition (UHD) and high definition (HD) endoscopic systems for transoral endoscopic thyroidectomy
}

\author{
Jong-hyuk Ahn, Jae Hwan Kim, Jin Wook Yi, Min Hee Hur \\ Department of Surgery, Inha University Hospital, Incheon, Korea \\ Contributions: (I) Conception and design: JW Yi; (II) Administrative support: JH Ahn, JW Yi; (III) Provision of study materials or patients: JH Ahn, \\ JW Yi; (IV) Collection and assembly of data: JH Ahn; (V) Data analysis and interpretation: JH Ahn, JW Yi; (VI) Manuscript writing: All authors; (VII) \\ Final approval of manuscript: All authors. \\ Correspondence to: Jin Wook Yi. Department of Surgery, Inha University Hospital, 27 Inhang-ro, Jung-gu, Incheon 22332, Korea. \\ Email: gnsljw@gmail.com.
}

Background: The transoral endoscopic thyroidectomy vestibular approach (TOETVA) is the most recently introduced method of minimally invasive thyroid surgery. To our knowledge, no studies have compared TOETVA outcomes using different laparoscopic systems. This study compared outcomes of TOETVA using conventional high definition (HD) and ultra-high definition (UHD) equipment.

Methods: Medical data and surgery videos of 62 patients who randomized to undergo thyroid lobectomy by TOETVA using an HD or UHD system from August 2018 to April 2019 were retrospectively reviewed. Endoscopic procedures were divided into four phases: flap creation to isthmectomy (phase I); strap muscle division to upper pole ligation (phase II); trimming recurrent laryngeal nerve (phase III); and ligation of Berry's ligament to complete resection (phase IV).

Results: Of the 62 patients, 28 underwent TOETVA using an HD device and 34 using a UHD device. The clinical characteristics of the two groups were not different. Mean operating time for lobectomy was similar in the HD and UHD groups (44.19 \pm 9.94 versus $43.47 \pm 12.19 \mathrm{~min}, \mathrm{P}=0.825)$. The times required for phases I $(15.02 \pm 5.33$ versus $13.67 \pm 5.44 \mathrm{~min}, \mathrm{P}=0.397)$; II $(12.89 \pm 2.84$ versus $13.17 \pm 5.22 \mathrm{~min}, \mathrm{P}=0.816)$; III $(9.85 \pm 4.36$ versus $9.98 \pm 4.55 \mathrm{~min}, \mathrm{P}=0.918)$; and $\mathrm{IV}(6.43 \pm 3.69$ versus $6.65 \pm 3.45 \mathrm{~min}, \mathrm{P}=0.840)$ were also similar in the HD and UHD groups. The numbers of retrieved lymph nodes did not differ significantly in the HD and UHD groups $(3.26 \pm 2.62$ versus $3.45 \pm 2.81, \mathrm{P}=0.807)$.

Conclusions: Applying a UHD system in TOETVA resulted in outcomes similar to those observed with a conventional HD system. Operation time tended to be lower, especially for flap dissection, and numbers of harvest lymph nodes tended to be higher in the UHD group. Large-scale studies are needed to assess the advantages of the UHD system.

Keywords: 4K ultra-high definition camera; high definition camera; endoscopy; transoral thyroidectomy; thyroid neoplasms

Submitted Oct 05, 2019. Accepted for publication Jan 04, 2020.

doi: 10.21037 /gs.2020.01.06

View this article at: http://dx.doi.org/10.21037/gs.2020.01.06

(c) Gland Surgery. All rights reserved. 


\section{Introduction}

Although the anterior neck approach has been considered the standard for thyroid surgery, open thyroid surgery inevitably leaves a long surgical scar on the patient's anterior neck. Neck scars can reduce quality of life, especially for younger women who have higher rates of thyroid cancer than other populations (1). Alternative surgical approaches have therefore been developed, such that the surgical scar is located at less visible sites, including the armpits, breasts, and retroauricular area (2-4).

More recently, transoral endoscopic thyroid surgery was developed as a type of natural orifice transluminal endoscopic surgery (NOTES) for thyroidectomy $(5,6)$. Because incisions are made in the mucous membrane of the oral cavity, this method results in the more favorable cosmetic outcomes than other, previously introduced types of remote access thyroid surgery. A report on a transoral endoscopic thyroidectomy vestibular approach (TOETVA) in 60 patients showed no worrisome complications (7). This method has been adopted by many centers worldwide, as it is regarded as a promising technique for minimally invasive thyroid surgery $(8-10)$.

Laparoscopic/endoscopic surgery has involved the use of high definition (HD) endoscopic equipment, with a resolution of $1,920 \times 1,080$ ( 2 million) pixels. Improvements in display technology have led to the development of more advanced laparoscopic/endoscopic systems, such as three-dimensional endoscopic systems and ultra-high definition (UHD) systems $(11,12)$. Specifically, 4K-UHD laparoscopic/endoscopic devices have a resolution of $3,840 \times 2,160$ ( 8 million) pixels, allowing them to display more detailed views than HD devices (13). Compared with old standard-definition (SD) resolution equipment, which have a resolution of $720 \times 480(300,000)$ pixels, HD systems were found to improve the sophistication of surgical procedures, reduce complications, and shorten operative procedures $(14,15)$, suggesting that UHD equipment may similarly improve outcomes when compared with HD equipment. To our knowledge, however, no studies to date have compared the outcomes of UHD and HD equipment (13), including for TOETVA in patients undergoing thyroid surgery. Recently, our center installed a UHD endoscopic system in the operating theatre. This report describes our initial experience with this system and compares outcomes of the UHD system with those of a conventional HD system, thereby assessing the safety and advantages of a UHD device in TOETVA.

\section{Methods}

\section{Laparoscopic systems: HD versus $U H D$}

The HD system (Linvatec Corporation, FL, USA; Figure 1) is over 10 years old, has a resolution of $1,920 \times 1,080$ ( 2 million) pixels, a refresh rate of 50 or $60 \mathrm{~Hz}$, and a magnification power as high as $2 \times$ compared with the naked eye. The new 4K-UHD system (Arthrex Inc., FL, USA; Figure 2) is only 1 year old, has a resolution of $3,840 \times 2,160$ (8 million) pixels with 30 billion colors, a refresh rate of 60 $\mathrm{Hz}$, and a magnification power as high as $4 \times$ compared with the naked eye. Patients were randomly allocated to undergo surgery using the HD or UHD system according to the hospital's daily surgery schedule.

\section{Dividing the surgical phase}

To evaluate the details of the endoscopic phase of TOETVA, the procedure used was divided into four surgical phases. Phase I was defined as the procedure from flap creation to thyroid isthmus division; phase II as the procedure from dissection of the thyroid lateral side from the adjacent strap muscle to completion of superior pole ligation; phase III as the entire process of finding and trimming the recurrent laryngeal nerve (RLN); and phase IV as the procedure from the dissection of Berry's ligament to complete thyroid resection, with/without enbloc resection of central lymph nodes. All video clips were reviewed by three endocrine surgeons (JH Ahn, JH Kim, and JW Yi), who determined the time points by consensus.

\section{Study design and data analysis}

This study was designed as a non-inferiority study to show that UHD endoscopic devices were as usable as conventional HD systems for TOETVA. The electronic medical records and video clips of patients who underwent thyroid lobectomy using TOETVA with the HD and UHD devices from August 2018 to April 19 were retrospectively reviewed. Factors analyzed included clinical information, surgery notes, and pathology reports. For simple comparison of surgical details, only patients who underwent lobectomy were included. All operations were performed 

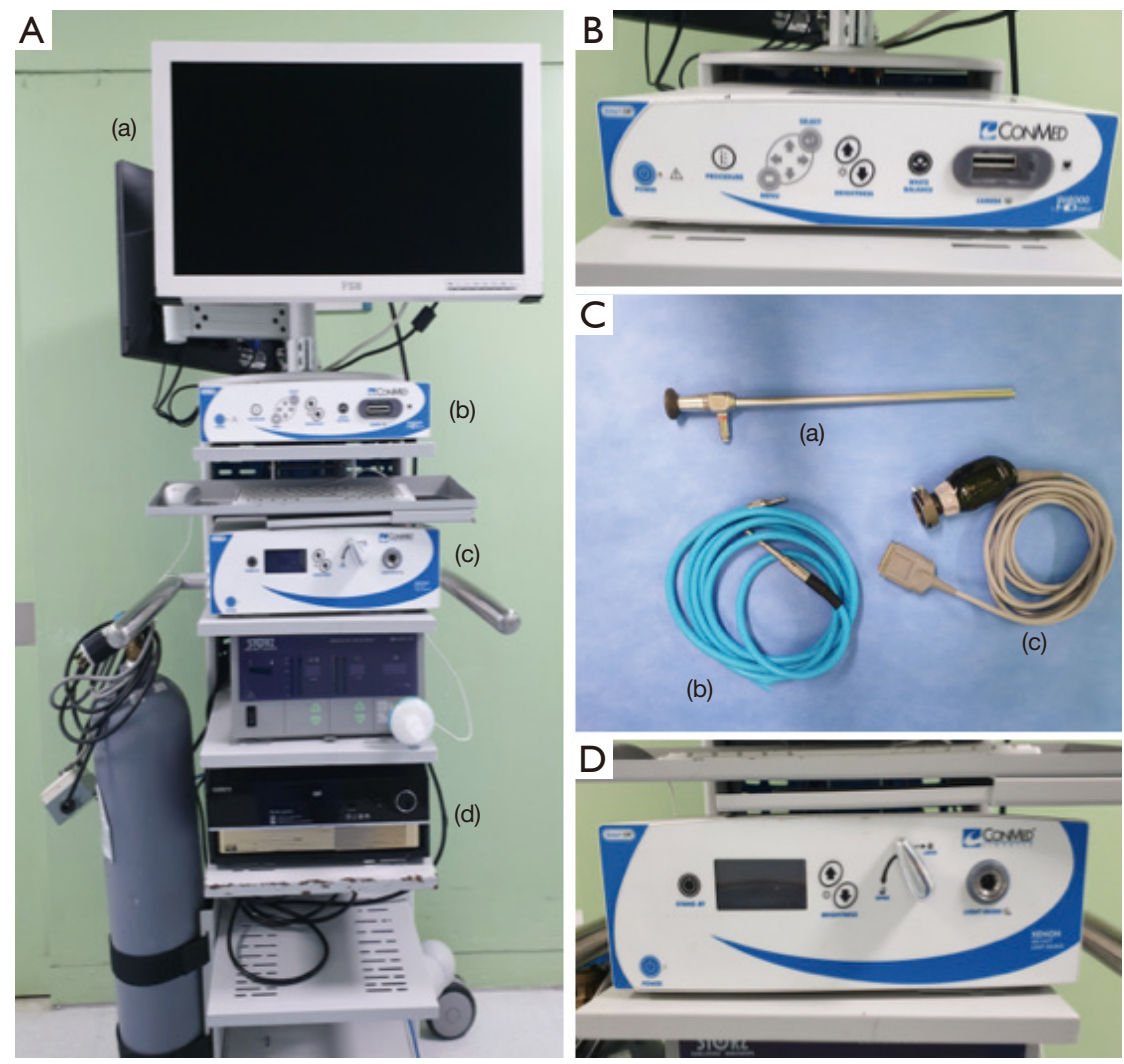

Figure 1 Components of high definition (HD) system. (A) Overall appearance: (a) 26-inch HD display, (b) camera control unit, (c) light source, and (d) HD recorder; (B) close-up of the camera control unit; (C) close-up of an HD endoscope model: (a) HD endoscope, (b) light cable, and (c) HD 3 metal oxide semiconductor (3MOS) chip camera head; (D) light source.

by a single endocrine surgeon who had performed more than 100 such operations before this study. Details of the TOETVA procedure, preoperative management, and evaluation of postoperative complication were previously reported $(10,16)$. Patients suspected of papillary thyroid cancer (PTC) and those with PTC (Bethesda categories V and VI, respectively) also underwent ipsilateral central neck lymph node dissection.

Criteria for TOETVA have been described (16). These include thyroid nodules identified as PTC, suspicious of PTC, or follicular neoplasm, based on the results of fine needle aspiration cytology (FNAC), tumors $\leq 2 \mathrm{~cm}$ in diameter on preoperative ultrasonography, intrathyroidal nodules, no evidence of central or lateral compartment neck lymph node metastasis, and no history of neck or oral surgery. Patients with benign nodules as large as $8 \mathrm{~cm}$ located on the mid to lower pole were also candidates for TOETVA.

Postoperative pain scores, as assessed on a visual analog scale (range, 0-10) were recorded daily at 6:00 am. Postoperative vocal cord function was measured by laryngeal ultrasound (17), with a cutoff between transient and permanent vocal cord palsy of 6 months. Mental nerve injury was defined as the occurrence of paresthesia or paralysis around the chin and was analyzed as previously described (16).

All statistical analyses were performed using SPSS version 20 software (SPSS; IBM Corporation, NY, USA). Categorical variables were analyzed by chi-square or fisher's exact test, and continuous variables by unpaired $t$-tests. $\mathrm{P}$ values $<0.05$ were considered statistically significant. The study protocol was approved by the Institutional Review Board (IRB) of Inha University Hospital (approval number: INHAUH 2019-05-003).

\section{Results}

Of the 62 patients who underwent TOETVA, 28 underwent surgery using the HD system, and 34 underwent 

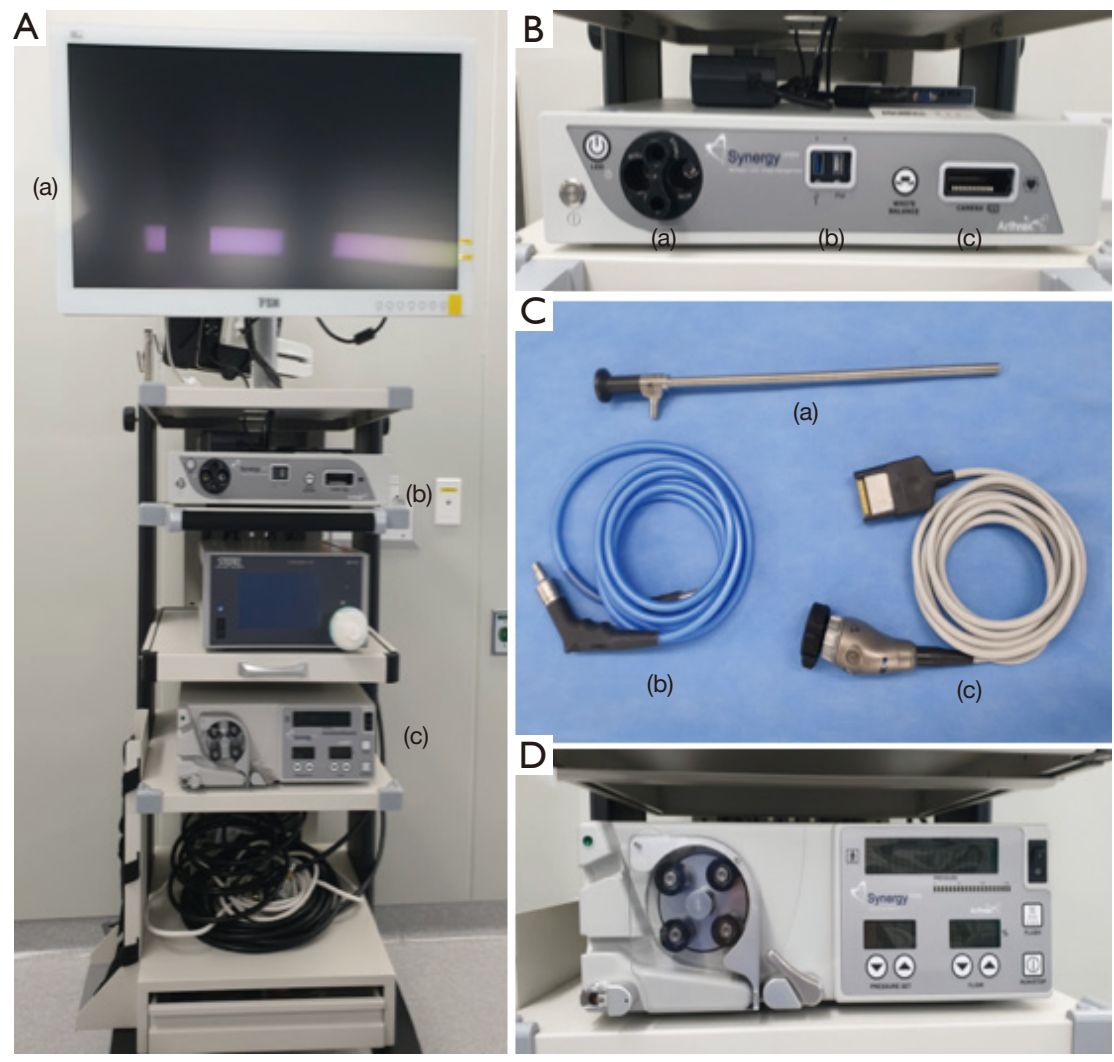

Figure 2 Components of 4K ultra-high definition (UHD) system. (A) Overall appearance: (a) 32-inch UHD medical monitor, (b) UHD all-in-one imaging console, and (c) irrigation pump unit; (B) a UHD all-in-one imaging console with a built-in picture archiving and communication system (PACS): (a) light source, (b) UHD recorder, and (c) camera control unit; (C) a UHD endoscope model: (a) UHD endoscope, (b) light cable, and (c) UHD 3 chip charge coupled device (CCD) camera head; (D) irrigation pump unit.

surgery using the UHD system. Table 1 shows the clinical characteristics of these two groups. All patients were women, with mean ages not differing significantly between the HD and UHD groups $(37.36 \pm 10.82$ versus $41.79 \pm 10.24$ years, $\mathrm{P}=0.103)$. Preoperative analysis of FNAC samples of the nodules $(\mathrm{P}=0.743)$ and tumor location $(\mathrm{P}=0.980)$ did not differ significantly between these two groups.

Figures 3,4 show representative endoscopic views of patients undergoing TOETVA with the HD and UHD systems, respectively. Figure $3 A, B$ show isthmectomy with the HD and UHD systems, respectively (phase I); Figure $3 C, D$ show upper pole dissection while preserving the upper parathyroid gland with HD and UHD, respectively (phase II); Figure 3E, $F$ show the process of identifying the RLN with HD and UHD, respectively (phase III); and Figure $3 G, H$ show central compartment lymph node dissection with the HD and UHD systems, respectively (phase IV).
Table 2 compares surgical and pathologic variables in the HD and UHD groups. The mean operation time required for lobectomy was similar between the HD and UHD groups $(44.19 \pm 9.94$ versus $43.47 \pm 12.19 \mathrm{~min}$, $\mathrm{P}=0.825)$, as were the mean times for phases I $(15.02 \pm 5.33$ versus $13.67 \pm 5.44 \mathrm{~min}, \mathrm{P}=0.397)$, II $(12.89 \pm 2.84$ versus $13.17 \pm 5.22 \mathrm{~min}, \mathrm{P}=0.816)$, III $(9.85 \pm 4.36$ versus $9.98 \pm 4.55$ $\min , \mathrm{P}=0.918)$, and IV $(6.43 \pm 3.69$ versus $6.65 \pm 3.45 \mathrm{~min}$, $\mathrm{P}=0.840$ ). Estimated blood loss during surgery also did not differ significantly between the HD and UHD groups $(48.57 \pm 55.89$ versus $69.12 \pm 90.60 \mathrm{~mL}, \mathrm{P}=0.300)$.

Final pathological diagnoses of patients in the HD group were PTC in 19 patients (67.9\%), benign nodules in $7(25.0 \%)$, and follicular tumors in two $(7.1 \%)$, including one with a non-invasive follicular thyroid neoplasm with papillary-like nuclear features (NIFTP) and one with a follicular thyroid carcinoma (FTC). Final pathological diagnoses of patients in the UHD group were PTC in 
Table 1 Demographic and clinical characteristics of patients in the HD and UHD groups

\begin{tabular}{lccc}
\hline Variables & HD group $(\mathrm{n}=28)$ & $\begin{array}{c}\text { UHD group } \\
(\mathrm{n}=34)\end{array}$ & P value \\
\hline Age (years) & $37.36 \pm 10.82$ & $41.79 \pm 10.24$ & 0.103 \\
Gender & $28(100.0)$ & $34(100.0)$ & - \\
Female & $0(0)$ & $0(0)$ & \\
Male & & & \\
Preoperative FNAC & $8(28.6)$ & $10(30.3)$ & \\
Benign (II) & $0(0)$ & $2(6.1)$ & \\
AUS/FLUS (III) & $1(3.6)$ & $0(0)$ & \\
$\begin{array}{l}\text { FN or suspicious for } \\
\text { FN (IV) }\end{array}$ & $5(17.9)$ & $5(15.2)$ & \\
$\begin{array}{l}\text { Suspicious for } \\
\text { malignancy (V) }\end{array}$ & $14(50.0)$ & $16(48.5)$ & \\
Malignant (VI) & $15(53.6)$ & $17(50.0)$ & \\
Tumor location & $17(50.0)$ & \\
Left & & & \\
Right & & & \\
\hline
\end{tabular}

Values are presented as mean \pm standard deviation or number (\%). HD, high definition; UHD, ultra-high definition; FNAC, fine needle aspiration cytology; AUS/FLUS, atypia/follicular lesion of undetermined significance; FN, follicular neoplasm.

19 patients (55.9\%), benign nodules in $13(38.2 \%)$, and follicular tumors in $2(5.9 \%)$, including one each with NIFTP and FTC. There were no differences in postsurgical pathology between the two groups $(\mathrm{P}=0.598)$.

Overall maximal tumor diameter $(1.26 \pm 1.46$ versus $1.36 \pm 1.16 \mathrm{~cm}, \mathrm{P}=0.435)$ and PTC diameter $(1.28 \pm 1.53$ versus $1.33 \pm 1.21 \mathrm{~cm}, \mathrm{P}=0.628$ ) were similar between the HD and UHD groups. Similarly, the diameters of follicular type tumors, including FTC and NIFTP $(1.65 \pm 1.63$ versus $1.45 \pm 1.34 \mathrm{~cm}, \mathrm{P}=1.000)$, and the diameters of benign nodules $(1.09 \pm 1.43$ versus $1.39 \pm 1.15 \mathrm{~cm}, \mathrm{P}=0.499)$ were similar between the two groups.

Nineteen patients $(67.9 \%)$ in the HD group and 23 $(67.6 \%)$ in the UHD group underwent central lymph node dissection. The mean numbers of retrieved lymph nodes $(3.26 \pm 2.62$ versus $3.45 \pm 2.81, \mathrm{P}=0.807)$ and the mean numbers of metastatic lymph nodes $(0.57 \pm 1.12$ versus $0.34 \pm 0.72, \mathrm{P}=0.394)$ did not differ significantly.

Pain scores on postoperative days 1, 2, and 3 in these two groups (Table 3). Duration of hospital stay after surgery was significantly lower in the HD than in the UHD group ( $3.25 \pm 0.65$ versus $3.91 \pm 1.33$ days, $\mathrm{P}=0.019)$. No patient in either group experienced transient or permanent vocal cord palsy or mental nerve injury. Minor complications were observed only in the HD group, including one patient with a neck seroma requiring aspiration; one patient with flap site erythema and minimal signs of infection, which was completely resolved by treatment with antibiotics; and one patient with oral wound dehiscence.

\section{Discussion}

The quality of the endoscopic/laparoscopic equipment, including its resolution, sharpness, and stability, is important for maximizing the outcomes of video-assisted surgery. TOETVA is regarded as a minimally invasive method of thyroid surgery because it requires no skin incisions, and its subdermal flap area is narrower than that required for the transaxillary, breast-axillary, and retroauricular facelift techniques $(10,18)$. Several recent studies have reported the surgical and oncologic feasibility of TOETVA, with this method considered most successful by thyroid surgical societies worldwide $(10,18,19)$.

TOETVA allows the surgeon to move the endoscopic device. Initially, the monitor should be placed near the patient's foot because the endoscopic equipment enters through the mouth (20), making the distance between the monitor and the eye of the operator greater than during other types of endoscopic surgery, and making a larger sized monitor more helpful to the surgeon. In addition, bleeding in the surgical field can result in absorption of the red light by hemoglobin, reducing the amount of reflected light recognized by the charge coupled device (CCD). Generally, increased bleeding causes the screen to darken. Because TOETVA has a narrower operating field and its working space is shallow, screen darkening due to absorption of red light is an obstacle to safe endoscopic surgery.

Key to the performance of surgical laparoscopic/ endoscopic devices is the display, produced by the camera and monitor. The advantages of HD systems have resulted in their replacement of traditional SD devices $(14,15)$. Although UHD systems have a 4-fold higher resolution than HD systems, few studies to date have shown that the higher specificity of UHD endoscopic devices is helpful to surgeons, and none to our knowledge have compared these systems for TOETVA.

The UHD device used at our institution has a resolution of 3,840×2,160 (8 million) pixels with 10-bit color. UHD 

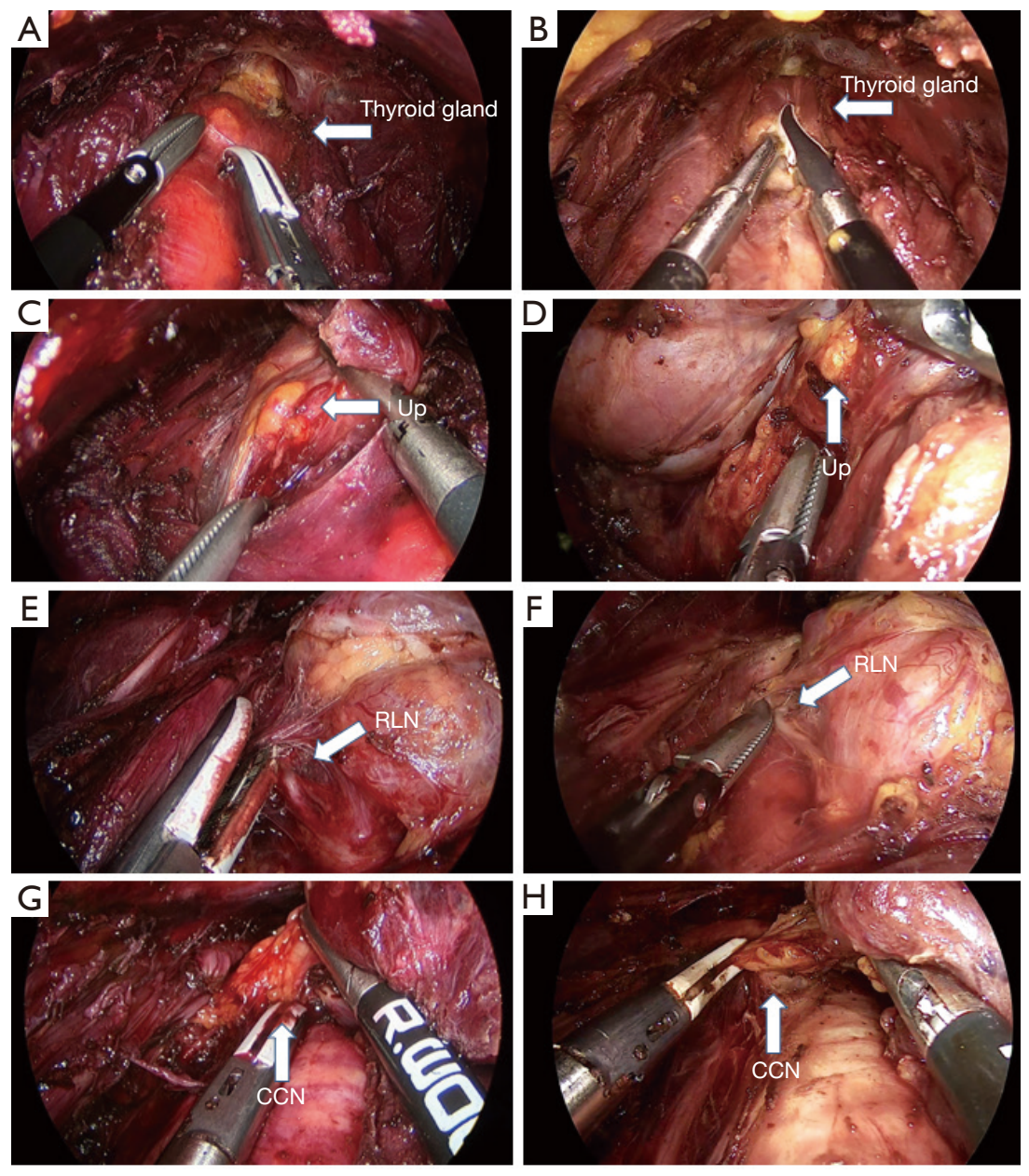

Figure 3 Operating fields of the HD (A,C,E,G) and UHD (B,D,F,H) systems according to surgical phase. (A) Isthmectomy with the HD system (phase I); (B) isthmectomy with the UHD system (phase I); (C) dissection of the superior pole while saving the left upper parathyroid gland using the HD system (phase II); (D) dissection of the superior pole while saving the left upper parathyroid gland using the UHD system (phase II); (E) identification of the left recurrent laryngeal nerve with the HD system (phase III); (F) identification of the left recurrent laryngeal nerve with the UHD system (phase III); (G) central compartment lymph node dissection in the HD system (phase IV); (H) central compartment lymph node dissection in the UHD system (phase IV). UP, upper parathyroid gland; RLN, recurrent laryngeal nerve; CCN, central compartment lymph nodes.

images show enhanced depth perception and produce more accurate colors than HD images. The UHD system also supports both 10- and 5-mm endoscopic cameras, which can monitor output of up to 55 inches. In addition, the advanced structure of the CCD and the high color density, up to 30 billion, can minimize screen darkening caused by bleeding during surgery.

To our knowledge, the present study is the first to compare HD and UHD devices for endoscopic system application in TOETVA. This study showed that using the UHD equipment yielded outcomes that were not inferior to those obtained using conventional HD equipment, and that the UHD equipment can be used safely in TOETVA. Although differences were not statistically significant, use of the UHD device may shorten operation times. Although total operation times were similar, use of the UHD device shortened flap creation time by about $2 \mathrm{~min}$. The absence of important anatomic structures may allow flap creation to be performed more easily with the higher resolution system.

Surgical outcomes, including bleeding during surgery, postoperative pain scores, vocal cord palsy, and other complications, did not differ significantly between the two 

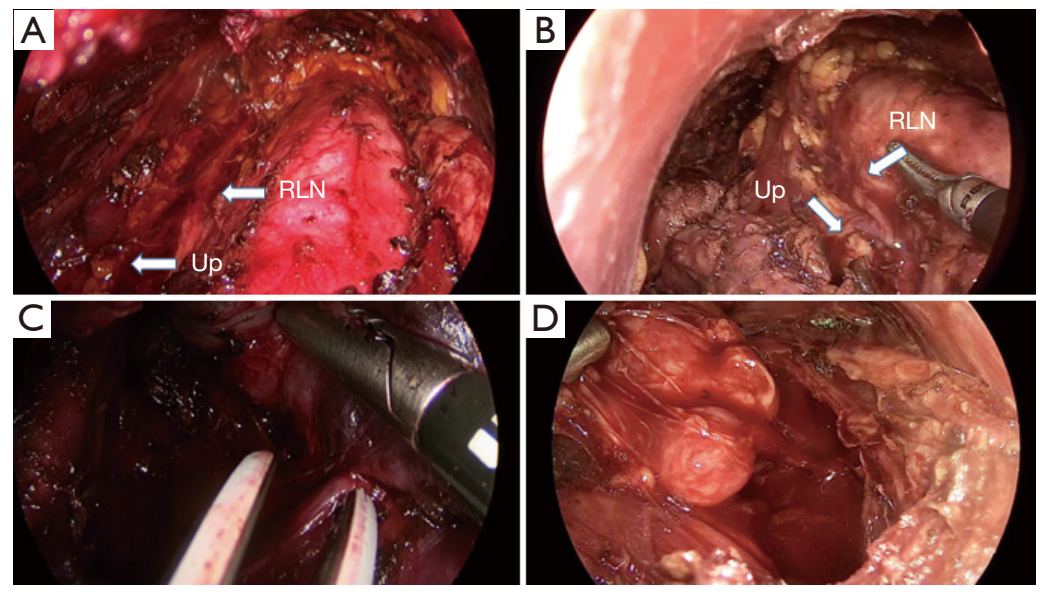

Figure 4 Operating fields of the HD (A,C) and UHD (B,D) systems after lobectomy (A,B) and at the time of bleeding (C,D). (A) After lobectomy in the HD system; (B) after lobectomy in the UHD system; (C) operation with the HD endoscopic system resulting in a large amount of bleeding, causing a poor visual outcome due to the absorption of red color by dark blood; (D) operation with the UHD system, showing that this system was less affected by red color absorption than the HD system, even if a large amount of bleeding occurred. UP, upper parathyroid gland; RLN, recurrent laryngeal nerve.

Table 2 Surgical and pathologic characteristics of patients in the HD and UHD groups

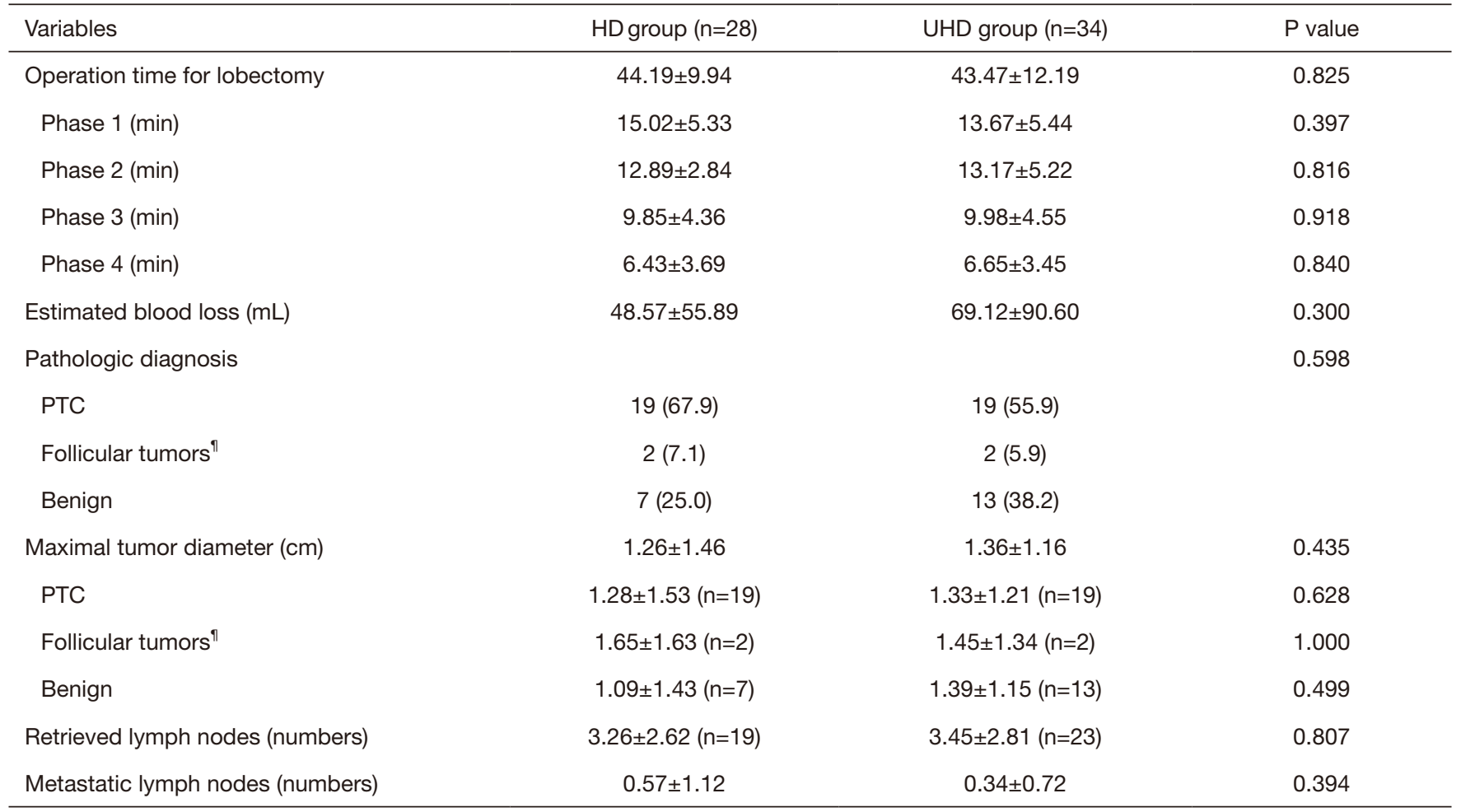

Values are presented as mean \pm standard deviation or number (\%). ", follicular tumors include follicular thyroid cancer and non-invasive follicular thyroid neoplasm with papillary-like nuclear features. HD, high definition; UHD, ultra-high definition; PTC, papillary thyroid cancer. 
Table 3 Postoperative outcomes of patients in the HD and UHD groups

\begin{tabular}{lccc}
\hline Variables & $\begin{array}{c}\text { HD group } \\
(\mathrm{n}=28)\end{array}$ & $\begin{array}{c}\text { UHD group } \\
(\mathrm{n}=34)\end{array}$ & P value \\
\hline Pain score (VAS) & & & \\
Day 1 & $2.89 \pm 0.32$ & $2.97 \pm 0.39$ & 0.397 \\
Day 2 & $2.57 \pm 0.50$ & $2.65 \pm 0.54$ & 0.575 \\
Day 3 & $2.04 \pm 0.60$ & $2.26 \pm 0.57$ & 0.140 \\
Hospital stay (days) & $3.25 \pm 0.65$ & $3.91 \pm 1.33$ & 0.019 \\
Surgical complications & $3(10.7)$ & $0(0)$ & 0.087 \\
Vocal cord palsy & $0(0)$ & $0(0)$ & \\
$\quad$ Transient & $0(0)$ & $0(0)$ & \\
$\quad$ Permanent & $0(0)$ & $0(0)$ & \\
Mental nerve injury & $0(0)$ & $0(0)$ & \\
Seroma & $1(3.6)$ & $0(0)$ & 0.452 \\
Surgical site infection & $1(3.6)$ & $0(0)$ & 0.452 \\
Oral wound dehiscence & $1(3.6)$ & $0(0)$ & 0.452 \\
\hline
\end{tabular}

Values are presented as mean \pm standard deviation or number (\%). HD, high definition; UHD, ultra-high definition; VAS, visual analog scale; range, 0-10.

groups. Hospital stay was longer in the UHD group, but the difference was not clinically significant. Most patients were discharged after 2 or 3 days, mostly at their discretion. Patients in the UHD group were older, which may have contributed to their longer hospital stay. Although not statistically significant, the numbers of retrieved central neck lymph nodes were higher in the UHD group, perhaps because of the wider and more detailed view of the level VI area provided by the UHD system.

The quality of the endoscopic instrument has minimal effect on surgical outcomes of operations performed by skilled surgeons. All procedures in the present study were performed by a single experienced surgeon who had performed more than 100 TOETVA operations. Higher quality endoscopic instruments may be helpful for novice surgeons, with one study reporting that UHD significantly improved speed and accuracy compared with 2D systems for procedures performed by a novice surgeon (21). Further research is needed to determine the usefulness of high-spec surgical instruments for less experienced surgeons.

This study had several limitations. First, it was not a prospective randomized controlled trial. Second, it included a relatively small number of patients. Third, all operations were performed by a single skilled surgeon. Large-scale prospective randomized controlled trials are required, as well as studies of the usefulness of the 4K-UHD endoscopic system for operations performed by novice surgeons.

\section{Acknowledgments}

Funding: This work was supported by a research grant from Inha University Hospital.

\section{Footnote}

Conflicts of Interest: All authors have completed the ICMJE uniform disclosure form (available at http://dx.doi. org/10.21037/gs.2020.01.06). The authors have no conflicts of interest to declare.

Ethical Statement: The authors are accountable for all aspects of the work in ensuring that questions related to the accuracy or integrity of any part of the work are appropriately investigated and resolved. The study protocol was approved by the Institutional Review Board (IRB) of Inha University Hospital (approval number: INHAUH 2019-05-003).

Open Access Statement: This is an Open Access article distributed in accordance with the Creative Commons Attribution-NonCommercial-NoDerivs 4.0 International License (CC BY-NC-ND 4.0), which permits the noncommercial replication and distribution of the article with the strict proviso that no changes or edits are made and the original work is properly cited (including links to both the formal publication through the relevant DOI and the license). See: https://creativecommons.org/licenses/by-nc-nd/4.0/.

\section{References}

1. Jung KW, Won YJ, Kong HJ, et al. Prediction of Cancer Incidence and Mortality in Korea, 2019. Cancer Res Treat 2019;51:431-7.

2. Ikeda $Y$, Takami H, Niimi M, et al. Endoscopic thyroidectomy by the axillary approach. Surg Endosc 2001;15:1362-4.

3. Choe JH, Kim SW, Chung KW, et al. Endoscopic thyroidectomy using a new bilateral axillo-breast approach. World J Surg 2007;31:601-6.

4. Park JO, Kim SY, Chun BJ, et al. Endoscope-assisted facelift thyroid surgery: an initial experience using a new 
endoscopic technique. Surg Endosc 2015;29:1469-75.

5. Witzel K, von Rahden BH, Kaminski C, et al. Transoral access for endoscopic thyroid resection. Surg Endosc 2008;22:1871-5.

6. Benhidjeb T, Wilhelm T, Harlaar J, et al. Natural orifice surgery on thyroid gland: totally transoral video-assisted thyroidectomy (TOVAT): report of first experimental results of a new surgical method. Surg Endosc 2009;23:1119-20.

7. Anuwong A. Transoral Endoscopic Thyroidectomy Vestibular Approach: A Series of the First 60 Human Cases. World J Surg 2016;40:491-7.

8. Dionigi G, Bacuzzi A, Lavazza M, et al. Transoral endoscopic thyroidectomy via vestibular approach: operative steps and video. Gland Surg 2016;5:625-7.

9. Park JO, Kim MR, Kim DH, et al. Transoral endoscopic thyroidectomy via the trivestibular route. Ann Surg Treat Res 2016;91:269-72.

10. Ahn JH, Yi JW. Transoral endoscopic thyroidectomy for thyroid carcinoma: outcomes and surgical completeness in 150 single-surgeon cases. Surg Endosc 2020;34:861-7.

11. Mercante G, Battaglia P, Manciocco V, et al. Threedimensional minimally invasive video-assisted thyroidectomy: preliminary report. J Exp Clin Cancer Res 2013;32:78.

12. Ohigashi S, Taketa T, Shimada G, et al. Fruitful first experience with an $8 \mathrm{~K}$ ultra-high-definition endoscope for laparoscopic colorectal surgery. Asian J Endosc Surg 2019;12:362-5.

13. Rigante M, La Rocca G, Lauretti L, et al. Preliminary experience with $4 \mathrm{~K}$ ultra-high definition endoscope: analysis of pros and cons in skull base surgery. Acta Otorhinolaryngol Ital 2017;37:237-41.

Cite this article as: Ahn JH, Kim JH, Yi JW, Hur MH. Comparison between the $4 \mathrm{~K}$ ultra-high definition (UHD) and high definition (HD) endoscopic systems for transoral endoscopic thyroidectomy. Gland Surg 2020;9(2):229-237. doi: 10.21037 /gs.2020.01.06
14. Marcus HJ, Hughes-Hallett A, Cundy TP, et al. Comparative effectiveness of 3 -dimensional vs 2-dimensional and high-definition vs standard-definition neuroendoscopy: a preclinical randomized crossover study. Neurosurgery 2014;74:375-80; discussion 380-1.

15. Hagiike M, Phillips EH, Berci G. Performance differences in laparoscopic surgical skills between true high-definition and three-chip CCD video systems. Surg Endosc 2007;21:1849-54.

16. Yi JW, Yoon SG, Kim HS, et al. Transoral endoscopic surgery for papillary thyroid carcinoma: initial experiences of a single surgeon in South Korea. Ann Surg Treat Res 2018;95:73-9.

17. Wong KP, Woo JW, Youn YK, et al. The importance of sonographic landmarks by transcutaneous laryngeal ultrasonography in post-thyroidectomy vocal cord assessment. Surgery 2014;156:1590-6; discussion 1596.

18. Anuwong A, Ketwong K, Jitpratoom P, et al. Safety and Outcomes of the Transoral Endoscopic Thyroidectomy Vestibular Approach. JAMA Surg 2018;153:21-7.

19. Camenzuli C, Schembri Wismayer P, Calleja Agius J. Transoral Endoscopic Thyroidectomy: A Systematic Review of the Practice So Far. JSLS 2018. doi: 10.4293/ JSLS.2018.00026.

20. Sivakumar T, Amizhthu RA. Transoral endoscopic total thyroidectomy vestibular approach: A case series and literature review. J Minim Access Surg 2018;14:118-23.

21. Abdelrahman M, Belramman A, Salem R, et al. Acquiring basic and advanced laparoscopic skills in novices using two-dimensional (2D), three-dimensional (3D) and ultrahigh definition (4K) vision systems: A randomized control study. Int J Surg 2018;53:333-8. 